\title{
BREVE PANORAMA DA PESQUISA SOBRE A CONFESSIONALIDADE NA EDUCAÇÃO SUPERIOR NO BRASIL
}

\author{
BRIEF OVERVIEW OF THE RESEARCH ON CONFESSIONALITY \\ IN HIGHER EDUCATION IN BRAZIL
}

\section{BREVE PANORAMA DE LA INVESTIGACIÓN SOBRE LA CONFESSIONALIDAD EM LA EDUCACIÓN SUPERIOR EM BRASIL}

Rodrigo Tarcha Amaral de Souza

Centro Universitário Salesiano de São Paulo - UNISAL, unidade São José/Campinas, SP., Brasil

REsumo Este trabalho apresenta um breve panorama sobre a situação atual da pesquisa a respeito da confessionalidade na educação superior no Brasil, inquirindo acerca da sua natureza e lugar no universo acadêmico, suas implicações no cenário sociocultural e relação com o mercado educacional. Apoiado em autores que tratam do cenário econômico neoliberal mundial como pano de fundo das transformações do modelo de gestão, concepção e função das instituições de ensino superior confessionais, foram articulados cinco eixos temáticos e dois tipos de abordagem educacional mais recorrentemente, abordados na pesquisa sobre a confessionalidade na educação superior no Brasil. Esse é um tema pouco explorado como campo investigativo na área educacional, em parte por existir certo desinteresse e ao mesmo tempo, resistência em tratar sobre a confessionalidade, posto que, tanto outrora como hoje, esse segmento de IES representa, em certa medida, posição contrária à perspectiva utilitarista e produtivista que considera a educação como um serviço comercial. Há uma inquestionável pressão ideológica e operacional para que as IES revisem, respectivamente, suas concepções identitárias e funções socioculturais na comunidade.

Palavras-chave: Educação Superior; Confessionalidade; Neoliberalismo; Pesquisa.

Abstract This paper presents a brief overview of the current research situation regarding confessionality in higher education in Brazil, inquiring about its nature and place in the academic universe, its implications in the socio - cultural scenario and relation with the 
educational market. Supported by authors who deal with the global neoliberal economic scenario as the background for the transformations of the management model, conception and function of denominational higher education institutions, five thematic axes and two types of educational approach were most frequently dealt with in the research on confessionality in higher education in Brazil. This is a theme rarely explored as an investigative field in the educational field, partly because there is a certain disinterest and at the same time resistance in dealing with confessionality, since, both in the past and today, this segment of Higher Education Institutions represents, to some extent, to the utilitarian and productivist perspective that considers education as a commercial service. There is no doubt ideological and operational pressure for HEIs to review, both their identity conceptions and sociocultural functions in the community.

Key-words: Higher Education; Confessionality; Neoliberalism; Research.

RESumen Este trabajo presenta un breve panorama sobre la situación actual de la investigación acerca de la confesionalidad en la educación superior en Brasil, preguntando sobre su naturaleza y lugar en el universo académico, sus implicaciones en el escenario sociocultural y relación con el mercado educativo. Apoyado en autores que tratan del escenario económico neoliberal mundial como telón de fondo de las transformaciones del modelo de gestión, concepción y función de las instituciones de enseñanza superior confesionales, se articular cinco ejes temáticos y dos tipos de abordaje educativo más, recurrentemente, tratados en la investigación sobre la confesionalidad en la educación superior en Brasil. Este es un tema poco explorado como campo investigativo en el área educativa, en parte por existir cierto desinterés y al mismo tiempo, resistencia en tratar sobre la confesionalidad, puesto que, tanto otrora como hoy, este segmento de IES representa, en cierta medida, posición contraria a la perspectiva utilitarista y productivista que considera la educación como un servicio comercial. Hay una incuestionable presión ideológica y operacional para que las IES revisen, respectivamente, sus concepciones identitarias y funciones socioculturales en la comunidad.

Palabras-clave: Educación Superior; Confesionalidad; Neoliberalismo; Investigación.

\section{INTRODUÇÃo}

As instituições confessionais tiveram significativa atuação histórica na educação brasileira, contribuindo inclusive, com a criação e o desenvolvimento de instituições de ensino superior (IES) (VASSELAI, 2001; CUNHA, 1980; DURHAN, 2003). Estas foram, paulatinamente, se consolidando na primeira metade do século XX. Reconhecido esse importante papel das IES confessionais na implementação da educação superior brasileira, seja pela influência das concepções humanistas, pioneirismo na sistematização de programas de estudos, particularmente na década de 1960, ou pela participação na expansão da pós-graduação nacional entre outros fatores de ordem acadêmica, cabe refletir sobre esse seguimento universitário. Imerso num novo contexto político e econômico brasileiro de via neoliberal, esse segmento tem se ressentido da desarmoniosa relação entre igreja, IES confessional e 
mercado, posto que, cada vez mais, se tem tornado custoso para essas IES confessionais encontrar equilíbrio nessa relação triádica, o que gera impacto em suas concepções identitária, universitária e no seu papel sociocultural na comunidade, sobretudo em relação com o mercado (MUCKENBERGER, 2014; SILVA JÚNIOR, 2006).

O panorama da pesquisa sobre a confessionalidade na educação superior requer uma ampla e minuciosa exploração literária para compilação e sistematização de informações. Sendo um tema pouco explorado no campo educacional, serão apontados neste trabalho, assuntos que têm sido mais recorrentemente tratados e problematizados no universo acadêmico nas duas décadas do século XXI, compreendendo o contexto sociocultural e acadêmico, referencial normativo civil e eclesial, bem como, lançar pistas para futuros trabalhos sobre a confessionalidade na educação superior.

Este trabalho está estruturado em duas partes: contextualização do cenário da educação superior no Brasil, destacando sua evolução estrutural e metamorfose de concepção e função acadêmica e discussão a partir de eixos temáticos e tipos de abordagem educacional para análise da categoria "confessionalidade" na educação superior em algumas produções científicas.

\section{A EducaÇão Superior no Brasil: EvoluÇão e Metamorfose}

Alinhado com a doutrina neoliberal de que compete ao mercado a provisão de bens e serviços desejados pela sociedade, o Estado brasileiro tem favorecido condições para a concorrência do mercado educacional por meio de leis e decretos nas últimas décadas do século XX e início do XXI, tendo na Educação Superior um substancial instrumento do aparelhamento econômico da sociedade pelo setor empresarial. Friedman (1985) e Chesnais (1996) apresentam elementos detalhados sobre o capitalismo e a liberdade na produção, bem como, a mundialização do capital que guia e molda a sociedade conforme a cadência da financeirização econômica.

Imerso nesse cenário de nova divisão internacional do trabalho, Paulani $(2003 ; 2008)$ trata sobre a era neoliberal no Brasil, que abrange o período dos governos escolhidos por eleições democráticas. Sinaliza a mudança dos parâmetros políticos mundiais de um modelo desenvolvimentista para uma doutrina neoliberal, tendo suas raízes nos governos de Margaret Thatcher, primeira-ministra do Reino Unido de 1979 a 1990, e, Ronald Reagan, presidente dos Estados Unidos da América de 1981 a 1989. Ambos transformaram as orientações das atividades do Estado, abandonando o chamado "estado de bem-estar social", passando a apoiar o lado da oferta e estimulando a produção e o acúmulo de capital. Realidade absorvida pelos órgãos internacionais como o Banco Mundial, que passou a exercer influência em todas as nações dependentes do capital externo como o Brasil.

A implantação da doutrina neoliberal no Brasil gerou um acelerado crescimento do mercado educacional na Educação Superior. Sguissardi $(2006,2009 ; 2013)$ analisa a realidade da Educação Superior como bem antes privado que público, dado evidenciado pelo autor a partir de documentos institucionais do Banco Mundial, UNESCO, leis e decretos 
governamentais do Brasil que sinalizam esse alinhamento da Política Educacional brasileira ao modelo neoliberal que, para o autor, avançou para o modelo ultraliberal, caracterizado pelo monopólio e financeirização de instituições educacionais constituídas e conduzidas pelo capital aberto na bolsa de valores.

Para Souza (2001), o tipo de política educacional a ser perseguida está vinculado aos objetivos a serem alcançados na educação nacional. A política educacional voltada à Educação Superior é uma expressão fenomênica do capitalismo contemporâneo (GUEDES; MURANAKA; ARAGÃO, 2016). Submetidos à política econômica e educacional mundial de viés neoliberal não é de se estranhar o cenário de crescimento do mercado educacional brasileiro, que tem passado por uma reestruturação produtiva da qual sua organicidade se dá a partir da reforma gerencialista do Estado brasileiro (MACEDO, 2015). Mancebo, Vale e Martins (2015) e, Guedes, Muranaka e Aragão (2016) tratam dos pressupostos, fundamentos e tendências do processo de expansão e privatização da Educação Superior brasileira. Analisam e constatam impactos da mercantilização da formação e produção do conhecimento em uma economia mundializada.

Um elemento substantivo da globalização neoliberal presente na Educação Superior é, de longa data, a transformação dos currículos acadêmicos, tornando referencial o conhecimento de disciplinas técnicas e informacionais que agreguem eficácia e competitividade em detrimento do desenvolvimento das finalidades essenciais da formação humana integral (PAULANI, 2008). Para Dias Sobrinho (2015), este cenário corresponde a uma fratura da universidade.

Buarque (1994) recorda que a universidade tem um papel permanente de gerar saber de nível superior para viabilizar o funcionamento da sociedade. Essa produção e mobilização de saber se manifesta conforme o tipo de sociedade que se deseja e se fomenta. Até as primeiras décadas do século XX, podia-se dizer que as concepções de Educação Superior no Brasil tinham influência inglesa (ensino), alemã (pesquisa), francesa (profissionalização). A última mais presente até hoje, por ter desenvolvido o modelo de escola e Educação Superior como profissionalização (PROTA, 1987; DREZE; DEBELE, 1983). Na segunda década do século XX, a Educação Superior no Brasil adotou o modelo universitário norte-americano como parâmetro de desenvolvimento acadêmico por sintetizar as outras concepções universitárias, incluindo o aspecto compreendido, atualmente, como extensão acadêmica, ato de levar o conhecimento universitário para a comunidade local (CURY, 2005). É neste sentido que Teixeira (1998, p. 51) compreende que:

[...] nenhuma universidade pode visar mais alto do que ser tão britânica quanto possível, em relação aos seus graduandos, tão germânica quanto possível para os pós-graduandos e pesquisadores e tão americana quanto possível para o público em geral.

Percebido o avanço e/ou diluição da reelaboração das concepções e modelos de universidade, torna-se sintomático questionar o seu uso e função na sociedade. Para Kerr (1982), a chamada "multiversidade", um conglomerado de áreas científicas, públicos dis- 
tintos, universidades e sociedade, consistia num organismo de partes indissociáveis, revelando-se utópico e inconsistente na primeira metade do século XX nos Estados Unidos da América. Anísio Teixeira, em seu discurso de inauguração dos cursos da Universidade do Distrito Federal, em 31 de julho de 1935, trata sobre a função da universidade:

\footnotetext{
Trata-se de manter uma atmosfera de saber, para se preparar o homem que o serve e o desenvolve. Trata-se de conservar o saber vivo e não morto, nos livros ou no empirismo das práticas não intelectualizadas. Trata-se de formular intelectualmente a experiência humana, sempre renovada, para que a mesma se torne consciente e progressiva. Trata-se de difundir a cultura humana, mas de fazê-lo com inspiração, enriquecendo e vitalizando o saber do passado com a sedução, a atração e o ímpeto do presente (TEIXEIRA, 1998, p. 88).
}

A Educação Superior tem sido levada a abandonar o seu tradicional papel de construir conhecimento e transmitir formação como bem público. A mansão do saber e da liberdade, frase atribuída a Anísio Teixeira, referindo-se à genuinidade e legitimidade da universidade como lócus do conhecimento humanístico e cultural, tem cedido espaço para uma Educação Superior que adota o mercado como referência de sua produção (FERREIRA; OLIVEIRA, 2010). Uma metamorfose do espaço e finalidade acadêmica que Chauí (1999) chama de universidade funcional e operacional. A primeira consiste na rápida formação profissional de trabalhadores como "mão de obra", a segunda está estruturada por estratégias e programas de eficácia organizacional. Ambos formatos divergem da universidade clássica que primava pela construção e transmissão do conhecimento.

Próprio do paradigma técnico-industrial e da mundialização do capital, viu-se na Educação Superior a panaceia de todo o desenvolvimento sociocultural, sem considerar o real sentido social da universidade. Goergen (2002) recupera essa questão a partir das funções de ensino, pesquisa e extensão acadêmica. Percebe que a promessa do progresso social de desenvolvimento humano pela via técnico-industrial é parcial e incompleta. Reconhece nas demandas sociais o ponto de partida para que de maneira legítima, a Educação Superior possa construir o conhecimento que não esteja alinhado somente ao modelo socio-econômico, que de modo costumeiro, se mantêm subserviente ao mercado utilitarista e utilitário. Para refletir sobre a dimensão social da Educação Superior, de modo prevalente, cabe tratar a respeito do Ensino Superior comunitário ${ }^{1}$ e confessional, tomando o último como recorte temático para uma revisão de literatura.

1 Entre as IES comunitárias e confessionais há semelhanças de ordem jurídica e distinções de ordem pedagógica e social. Para um melhor aprofundamento sobre as IES comunitárias, consultar as obras de Bittar (1999) que trata da construção da identidade comunitária nas IES; Schmidt (2010) que aborda o assunto das IES comunitárias como não estatal; Aquino (2017) que trata da ação comunitária numa IES: um estudo de caso. 


\section{A confessionalidade na EducaÇão Superior}

O desenvolvimento do Ensino Superior confessional no Brasil ocorre em paralelo ao da universidade pública, a partir da década de 1940, ainda que tenha acumulado atuação anterior no ensino superior. (TAVARES, 2012). Esse período ficou conhecido como a "Era Vargas", marcado por tensões entre correntes liberais e totalitárias. Em 1946, o governo vigente apoiou o reconhecimento do Instituto Sedes e da Universidade Católica de São Paulo, ambas na cidade de São Paulo e, no Rio de Janeiro, a Universidade do Rio de Janeiro. (VASSELAI, 2001). Entende-se que na condição de Estado centralizador no uso e função dos poderes, o governo pretendesse controlar a função político-ideológica do ensino superior, que no caso do ensino superior confessional, dogmático pela correspondência a uma doutrina religiosa, e tradicional pela preservação dos costumes morais de natureza cristã, legados do tempo da colônia, império e primeira república, se alinhava ao Estado no reforço de uma consciência nacional.

Nesse período de governos populistas, buscou-se integrar o aparelho escolar às respostas da necessidade do povo e, ao mesmo tempo, o Estado queria um ensino superior modernizado para satisfazer às exigências técnicas necessárias ao desenvolvimento autônomo almejado. O pano de fundo consistia na acelerada industrialização brasileira, que resultou na ascensão social das camadas médias e daí a procura pelo diploma. (VASSELAI, 2001).

É nesse sentido que, com a Reforma Universitária de 1968, houve uma maior abertura para o Ensino Superior privado no Brasil, uma vez que as modificações introduzidas nas universidades públicas não foram suficientes para ampliar suas matrículas e atender à crescente demanda de acesso.

Segundo Martins (2009, p. 2):

A Reforma de 1968 produziu efeitos paradoxais no Ensino Superior brasileiro. [...] modernizou uma parte significativa das Universidades federais e determinadas instituições estaduais e confessionais, que incorporaram gradualmente as modificações acadêmicas propostas pela Reforma. Criaram-se condições de ensino e de pesquisa, que até então salvo raras exceções - estavam relativamente desconectadas.

Antes da Reforma Universitária de 1968, o Ensino Superior privado, predominantemente cristão, de caráter católico, permanecia dependente dos financiamentos do poder público. (ANTONIAZZI, 1975). Após a Reforma, o Ensino Superior privado estruturou-se num molde de empresa educacional, voltado para a obtenção do lucro econômico e ao rápido atendimento da demanda de mercado educacional. Não obstante, o ensino universitário católico mostrou-se reticente em expandir sua rede para absorver essa demanda, mantendo uma concepção de universidade voltada ao atendimento da reprodução das elites locais (SALEM, 1982).

Recuperados os pressupostos e fundamentos da doutrina neoliberal no Brasil, assunto tratado no tópico anterior, assistimos, hoje, a uma transformação profunda no modo como 
é entendida e posta em prática a regulação das políticas educacionais, no contexto de uma alteração mais ampla relacionada com a própria concepção, reforma e reestruturação do Estado e da sua administração, também do Ensino Superior. Nesse sentido, nas últimas décadas, o Brasil apresentou um forte alinhamento de princípios neoliberais, guiando-se por critérios de eficácia, produtividade e excelência para legislar o rumo das políticas educacionais voltadas ao Ensino Superior. (SGUISSARDI, 2009).

Nesse cenário de efervescência ideológica neoliberal, capaz de impingir uma nova lógica, finalidade e função da universidade, não tem sido fácil identificar e reconhecer a identidade das instituições de Ensino Superior Confessionais, bem como legitimá-las como idôneas na condução do justo equilíbrio entre a autonomia universitária, aplicação de políticas voltadas para o Ensino Superior e o desenvolvimento de sua identidade institucional confessional (ALVIM, 1995). Permeado por esse pano de fundo ideológico neoliberal presente nas políticas educacionais e epistemologias orientativas da Educação Superior, requer-se, necessariamente, conceituar o termo confessional do ponto de vista normativo e literário para compreender o seu significado, alcance, limites e implicações na Educação Superior.

A partir de referencial normativo, temos os artigos 209 e 213 da Constituição da República Federativa do Brasil. No primeiro texto, o artigo 209 apresenta a possibilidade de atuação da livre iniciativa no campo educacional, mediante autorização e avaliação de sua qualidade pelo poder público e o cumprimento da normativa aplicável à educação. No segundo texto o artigo 213, inciso II, trata de sua finalidade não lucrativa, aplicando, por sua vez, os excedentes em educação. De maneira complementar, mas ao mesmo tempo operacional, tem-se a Lei 9.394, Lei de Diretrizes e Bases da Educação (LDB), aprovada em 1996. Em seu artigo 20, inciso II, afirma ser uma instituição confessional "enquanto prestam serviço pedagógico em cumprimento a sua missão específica" (LDB, art. 20 II). Se, por um lado o referencial normativo não abrange a totalidade do conceito "confessionalidade", por outro, afirma de sua configuração jurídica, ação pedagógica, e social.

O referencial normativo eclesial no âmbito da Educação Superior abrange matrizes denominacionais distintas. Respeitadas suas especificidades carismáticas, supõe a síntese da “fé e saber científico e cultural". É necessário recordar que a concepção de universidade confessional numa perspectiva orgânica se dá a partir do concílio Vaticano II realizado de 1962 a 1965, que renovou critérios e parâmetros da igreja na relação ecumênica, inter-religiosa e com/no mundo. Há de se reconhecer, porém, que, mesmo em documentos eclesiais recentes, (ECE, 1990; CNBB, doc. 102, 2013) ${ }^{2}$ há ainda, sutilmente, certa prevalência da fé sobre o saber, o que numa perspectiva de ordem prática, constata-se o contrário na medida em que IES confessionais são submetidas, quando por si só não se inclinam a adotar modelos de gestão gerencialista, proveniente da doutrina neoliberal. Somente uma leitura

2 Há um entendimento de que a reflexão orgânica entre fé e razão é incipiente nos meandros das IES confessionais, tanto de natureza católica como protestante, existindo certa prevalência da fé sobre a razão na concepção e modo de gerir a política acadêmica desses espaços. Os estudos de MUCKENBERGER (2014) e SILVA JÚNIOR (2006) apontam uma substancial dicotomia entre as esferas razão (cultura acadêmica) e fé (preceito denominacional), que, por sua vez, justifica a escassez de documentos oficiais que contemplem a organicidade entre ciência, razão e fé nas IES confessionais, sobretudo, de matrizes protestantes. 
arguta desses documentos pode inferir dessa tênue síntese entre fé e saber como elementos indissociáveis nas IES confessionais.

Confessionalidade deriva do radical "confessar", e não tem registro no Dicionário Aurélio de Língua Portuguesa, por ser recente na história e/ou não apresentar ainda uma definição popular assumida pela cultura. Por confessional, entende-se a relação com a confissão de crença religiosa e/ou culto da religião, que de modo tradicional e popular, naturaliza-se em saberes e práticas educativas em escolas formais e não-formais.

O conceito confessionalidade não é recorrente em produções científicas que ultrapassem a esfera das ciências teológicas e do campo da fé popular. Silva Júnior (2006) trabalha a confessionalidade como uma categoria de estudo representativa de uma contradição regida pela história produzida pelos seres sociais. Concebe a entrada da confessionalidade no ensino superior mais pela sobrevivência institucional de ordem econômica do que identitária, não negando, obviamente, a complementariedade dos dois aspectos.

De maneira mais enfática, Tavares (2012) constata que a identidade confessional é algo indefinido, estando ainda em debate no campo. Parte do raciocínio de que o Ensino Superior Confessional não é público por não pertencer ao governo, mas também não é privado por não ser propriedade particular regido por lógica empresarial, o que torna difícil sua conceituação e definição.

Os autores (VASSELAI, 2001; METZLER, 2011; ALVIM, 1995) reconhecem a relação da confessionalidade com o poder instituído que, por sua vez, legitimam o campo da fé. Para Vasselai (2001), a confessionalidade, expressão de religiosidade, se materializa no ato educativo que possibilita o "aprender a ser", ainda que em momentos diversos, a confessionalidade esteja vinculada ao poder constituído. De modo semelhante, Metzler (2011) entende ser a confessionalidade, em forma de poder religioso como a expressão do poder legitimado, ou seja, a representação da identidade institucional de parâmetros religiosos. Alvim (1995) acrescenta a reflexão da confessionalidade como construtora do reino espiritual, devendo ser compreendida de maneira ampla e não limitadora da autonomia universitária, justamente por ser um conceito dinâmico e não hermético.

Tavares (2012) e Cardoso (2016) afirmam do pertencimento da instituição universitária à igreja que a dirige. Associam o confessional à ação comunitária, sendo a última parte integrante da identidade confessional. Sua identidade resulta dessa mistura entre crença religiosa, atividade social e educacional que, concretizadas num contexto peculiar, têm sido o seu propósito através dos tempos.

Cericato (2006) e Moraes (2013) tratam a confessionalidade como pano de fundo de seus estudos, sendo definida pelo amparo legal constitucional e de comparação com o segmento comunitário como construção identitária. Gonçalves (2009) reconhece a complexidade da conceituação do termo confessional na educação superior por representar uma divergência com as concepções tradicionais de universidade, sobretudo a positivista, fortemente presente nas estruturas acadêmicas. Passos Júnior (2011), Tavares (2012), Vasselai (2001) e Cruz (2008) concebem a confessionalidade na Educação superior como uma síntese orgânica entre fé e saber manifesta nos acontecimentos e cotidiano acadêmico. 
Para Passos Júnior (2011, p. 306):

Uma escola de ensino superior não é uma sucursal de uma paróquia. Uma universidade confessional, deve, porém, estabelecer um diálogo adulto com a cultura fazendo com que os educandos tenham acesso ao pensamento antropológico e social dessa instituição.

Para Tavares (2012, p. 64), “O que diferencia o confessional é a articulação entre fé e razão e sua capacidade em expressar valores que possam nortear práticas de ensino, pesquisa e extensão, indo além da instrumentalidade e da funcionalidade das políticas acadêmicas". Vasselai (2001, p. 22) entende que: "[...] um projeto institucional confessional pretende completar o processo educativo enriquecendo as ações acadêmicas e favorecendo uma maior interiorização das ações humanas”. Para Cruz (2008, p. 72), “[...] a confessionalidade acrescenta à missão acadêmica um sentido que se sobrepõe a ação científica, enriquecendo e contribuindo para a formação do ser humano".

A utilização dessas produções científicas para conceituar a confessionalidade na educação superior permite entender o lugar que esta ocupa no espaço acadêmico. Ciente da diversidade de leituras e visões desta conceituação, percebe-se, conforme afirmado por Silva Júnior (2006), a contradição epistemológica de grupos denominacionais em aderir a um novo ramo educacional, da educação básica para a educação superior, mais por sobrevivência institucional do que preceitos religiosos, embora o mesmo esclareça que esses dois aspectos nunca estão desassociados. De certa maneira, embora todas as produções científicas apresentem, algumas sutilmente, que a confessionalidade é concebida pela relação com a dimensão espiritual, percebe-se, não obstante, o desajuste dos autores em lidar com o conceito confessional, seja pela vinculação do termo com o que é intangível, Deus, ou pelo interesse de desenvolver uma produção científica sobre uma estrutura física que, apenas por conveniência "espaço - temporal" se chama de confessional. Percebe-se, ainda em algumas produções, a não conceituação da confessionalidade, mas somente sua relação igualitária com o segmento comunitário e filantrópico de amparo legal.

Entende-se, portanto, que a conceituação da confessionalidade na educação superior demonstra ser um assunto ainda não suficientemente explorado, o que requer uma maior atenção a esse campo, por poder suscitar contribuições epistemológicas e operativas à Educação Superior de modo geral.

Ciente do risco de redução da complexidade da confessionalidade na educação superior a interpretações parciais e enviesadas, optou-se neste trabalho, por seguir o roteiro de identificar palavras-chave, rever fontes secundárias e depois primárias e, por fim, ler criticamente e resumir a literatura, a fim de que a apresentação do panorama da pesquisa sobre a confessionalidade na educação superior seja o mais abrangente e completo possível.

Para efeitos de credibilidade e segurança na obtenção de produções científicas provenientes de banco de dados de pesquisas, optou-se pela busca das palavras-chave no Banco de Teses da CAPES, Biblioteca Digital brasileira de Teses e Dissertações, artigos em 
periódicos de programas de Pós-Graduação em Educação ${ }^{3}$ que estivessem em bases de indexação, como: Scielo (Scientific Electronic Library Online), Edubase (Base de dados em Educação), BBE (Bibliografia brasileira de Educação), entre outros; além de produções científicas publicadas em eventos científicos relevantes da área de educação como a ANPEd (Associação Nacional de Pós-Graduação e Pesquisa em Educação). Cabe ressaltar a validade de se buscar também autores citados em vários trabalhos já lidos em pesquisa exploratória anterior.

Destaque para o Banco de Teses da CAPES e Biblioteca Digital brasileira de Teses e Dissertações por apresentarem uma maior amplitude de resultados. Comparativamente entre essas duas plataformas de acesso às produções científicas, o Banco de Teses da CAPES é o mais completo, mas a Biblioteca Digital realiza um melhor detalhamento de informações, apresentando trabalhos por região, instituição universitária e autoria, o que facilita a busca do pesquisador.

Numa primeira busca de produções científicas sobre a confessionalidade na Educação Superior, utilizou-se como palavra-chave "confessionalidade", aparecendo no Banco de Teses da CAPES apenas56 arquivos e no site da Biblioteca Digital, 31. O baixo número de arquivos revela a genericidade do termo como filtro de busca. Além do mais, uma parte expressiva dessas produções é proveniente de programas de Pós-Graduação em Teologia, e referenda a espiritualidade, elementos místicos e especificidades da área, condição inviável para uma reflexão e sistematização de dados de âmbito educacional. Numa segunda busca, com maior precisão das palavras-chave para a área da educação, foram obtidos resultados mais factíveis: 1) confessionalidade e políticas educacionais no ensino superior; 2) religião no Ensino Superior; 3) confessionalidade no ensino superior; 4) ensino superior confessional; e 5) identidade confessional no ensino superior. Para cada palavra-chave, diminuía o número de arquivos, confirmando a assertividade dos filtros de busca para todas as fontes e base de dados de produções científicas. ${ }^{4}$

Após longa busca, leitura de títulos, resumos, sumários e para alguns trabalhos, introdução e considerações, tem um número de 105 referências. Estabelecido o critério de relação direta com a investigação a ser desenvolvida, atualidade da produção científica e investigações procedentes de programas de Pós-Graduação, chegou-se ao número de dezesseis produções científicas a serem lidas, analisadas e resumidas para estabelecer parâmetros comparativos das questões que têm emergido na construção, desenvolvimento e operacionalização do segmento confessional na educação superior. Seguindo esses critérios, foram elaboradas quatro tabelas para uma melhor visualização e entendimento do as-

3 Cabe, de modo mais completo, uma ampla busca em outras fontes de produções científicas como programas de Pós-graduação em Ciências da Religião como a PUC-SP, UMESP, UFJF entre outros que, sob a ótica do fenômeno religioso, acrescentem dados a respeito da confessionalidade na educação superior, tanto em sua concepção como naturalização no meio acadêmico.

4 A expressão "ensino religioso", elemento pertencente à concepção de confessionalidade, foi uma das palavras- chave utilizadas para a busca de produções científicas. Sua relação genérica com a educação superior, e ao contrário, fortemente vinculada à educação básica, não contribuiu de maneira assertiva com o refinamento de busca de produções científicas referenciais para o desenvolvimento dessa investigação a respeito do panorama da pesquisa sobre a confessionalidade na educação superior. 
sunto, destarte a facilitar a junção e distinção de abordagens epistemológicas e perspectivas metodológicas.

Na primeira tabela, mais extensa, conformaram-se nove colunas, registrando: 1) o nome do autor (a); 2) o título da obra, ano e tipo de produção científica; 3) a área (de onde se fala), a procedência da instituição universitária e região; 4) o objetivo e o problema de pesquisa; 5) as referências que evidenciam os principais conceitos do trabalho; 6) o referencial teórico; 7) os procedimentos metodológicos; 8) as palavras-chave; e 9) os resultados. Com essas informações, foi possível visualizar a estrutura de cada produção científica, elaborando, em seguida, uma segunda tabela com a finalidade de tabular os seguintes dados: tipos de produção científica, somando seis dissertações, seis teses, três artigos e um livro; área de pesquisa com treze produções provenientes de programas de Pós-Graduação em Educação, dois em Administração e um em Ciências Sociais. Quanto à estrutura do trabalho, quatro se configuram como macroestrutural (análise ampla) e doze como microestrutural (análise local). Sobre a procedência regional e universitária, sete produções são provenientes da região sudeste (1 - UMESP); (3 - UNIMEP); (1 - UNICAMP); (1 - USP); e (1 - UFSCAR); a região sul com quatro produções, sendo: (1 - PUCRS); (1 - UNISINOS); (1 - UFSC) e (1 - UFP); a região centro oeste com duas produções: (1 - UCDB); e (1 - PUC GO), e mais três artigos de periódicos, totalizando dezesseis produções científicas. Exceto por uma produção de 1995, todas as outras pertencem aos anos 2000 em diante, com destaque para a última década. Quanto à matriz confessional e/ou algum tipo de vínculo institucional acadêmico dos autores, seis produções científicas apresentam matriz confessional católica, sete de matriz metodista, uma adventista e uma protestante [matriz confessional não definida no texto] e, em outro trabalho não foi identificado a matriz confessional.

Tendo compilado e tabulado as informações estruturais dessas produções, tornou-se possível apontar os eixos temáticos nucleares e secundários para cada produção científica de acordo com sua matriz confessional. Com esse material, deu-se origem à terceira tabela de informações com os seguintes eixos temáticos e tipos de abordagem educacional: 1) governança e gestão universitária; 2) internacionalização (redes); 3) materialização da confessionalidade na Antropologia e na Educação; 4) identidade institucional; 5) confessionalidade e mercado; A) abordagem educacional numa perspectiva histórica dividida em medieval, moderna e colonial; B) abordagem macro e micro-educacional. Destaque para os eixos temáticos "identidade institucional" e "confessionalidade e mercado" como os mais demarcados no desenvolvimento das produções referenciadas.

Por último, uma quarta tabela foi elaborada em forma de fichamento sobre o conceito e definição da confessionalidade na educação superior assumido pelos autores em suas produções. Conceito já apresentado neste trabalho, cujo caminho percorrido para sistematizar as informações revelam ser um trabalho de base que tem permitido atribuir sentido às relações estabelecidas entre as obras analisadas, podendo, assim, tecer interpretações acerca do cenário e panorama da pesquisa sobre a confessionalidade na educação superior no Brasil. 


\section{A Pesquisa sobre a Confessionalidade na Educação Superior no Brasil}

Estabelecidos os eixos temáticos e tipos de abordagem educacional das obras analisadas, embora sejam de naturezas diferentes, tornam-se complementares na medida em que, nucleados pela perspectiva confessional, favorecem uma melhor visualização do panorama da pesquisa sobre a confessionalidade na educação superior. Cabe recordar que as obras consideradas, bem como, seus eixos temáticos e tipos de abordagem educacional refletem o momento histórico de desenvolvimento econômico mundial de via neoliberal que, por sua vez, impele, forçosamente, adequações, para não dizer de uma completa transformação no modelo de gestão universitária que passa a adotar parâmetros performativos e gerenciais. Cenário contrastante com os parâmetros institucionais e de política acadêmica das IES confessionais que, tradicionalmente, se vinculam a modelos de gestão mais humanistas, com destaque para a participação coletiva nos fóruns de poder instituídos acadêmicos.

No primeiro eixo temático, governança e gestão universitária, foram analisadas as obras de Tavares (2009), artigo em educação publicado pela revista Educação \& Linguagem; Tavares (2012) e Alvim (1995), livro publicado pela editora UNIMEP, destacam o desafio das IES confessionais ultrapassarem a extensão de interesses primariamente religiosos, bem como alcançar a credibilidade como administradores e especialistas educacionais por essas IES ministrarem o ensino, conduzirem a pesquisa e alcançarem a comunidade com liberdade. Os trabalhos de Tavares (2009 e 2012) identificam os reflexos das mudanças de modelos de gestão nas IES confessionais, analisando o conceito de governança. Ele reconhece que um modelo de governança que considere as especificidades da IES confessional ainda está por ser construído. Moraes (2013), tese em educação desenvolvida na Universidade Federal do Paraná (UFP), apresenta matriz confessional católica. Investiga as implicações da adoção de um modelo de gestão empresarial competitivo, no contexto confessional comunitário. Por meio de pesquisa bibliográfica e de campo com as técnicas de questionário individual a 28 docentes, entrevista seis docentes e os depoimentos escritos de seis docentes, avalia que o caráter confessional age de forma semelhante às instituições comerciais, tanto na esfera administrativa como pedagógica.

No segundo eixo temático, a internacionalização da educação superior confessional, se enquadram as obras de Araújo (2009), dissertação em educação desenvolvida na Universidade Católica Dom Bosco (UCDB) de matriz confessional católica e Muckenberger (2014), tese em administração desenvolvida na Universidade de São Paulo (USP), de matriz confessional protestante, mas não identificado sua denominação. Araújo (2009) investiga como o processo de constituição e internacionalização da rede das instituições salesianas de educação salesiana (IUS) contribui para a afirmação da identidade confessional salesiana. Tendo realizado a análise de documentos institucionais da rede IUS, entende estarem plenamente inseridas no processo de mundialização econômica e das políticas para a educação superior, chegando a estabelecer uma relação dialética com esse cenário cultural e econômico mais amplo, ora aproximando-se e compactuando com suas tendências, ora sofrendo suas consequências e ora procurando distanciar-se para auto afirmar seus ideais 
e concepções. De modo semelhante, Muckenberger (2014) analisa o processo de internacionalização em um sistema de ensino superior internacional. Realizou um estudo de casos múltiplos (seis instituições de matriz cristã protestante), uma para cada continente, cujo sistema de ensino convencionou-se chamar de sistema "M". Acredita haver, atualmente, uma equiparação entre as motivações econômicas e as denominacionais, embora reconheça que se houver choque entre as motivações econômicas e denominacionais, se fará que se busquem os benefícios econômicos com maior cautela. Ambos os trabalhos permitem pensar na possibilidade de estudos futuros que destaquem a comparação do processo de internacionalização de sistemas de ensino confessionais e não confessionais; analisar a governança no sistema confessional internacional; estudar a relação entre os motivos denominacionais e os econômicos num estudo comparativo entre IES confessionais internacionais de matriz confessional diferentes.

O terceiro eixo temático, materialização da confessionalidade, está dividido em perspectiva antropológica e educacional. Compreende-se a expressão materialização da confessionalidade como a forma e consistência do conceito "confissão", tornando o trabalho religioso, pedagógico e econômico orgânico e ao mesmo tempo sistêmico. Na perspectiva antropológica, enquadra-se a obra de Passos Júnior (2011) que, por meio de fundamentos histórico, filosófico e teológico, se investiga como os princípios referenciais e procedimentos educativos salesianos do período fundacional das unidades salesianas de educação do século XIX chegam ao nosso tempo, cujo legado fundacional tem valor na medida em que são vivenciados por educadores e educandos em mútua relação educativa. Dessa maneira, conforme já salientado, o autor constata uma diluição desta materialização da confessionalidade de perspectiva antropológica no espaço das IES salesianas, posto que há certo desconhecimento dos fundamentos educativos salesianos por parte da coletividade acadêmica.

Com relação à perspectiva educacional, se enquadram nesse eixo as obras de Metzler (2011), tese em educação desenvolvida na Universidade do Vale do Rio dos Sinos (UNISINOS), de matriz confessional católica; e Vasselai (2001), trabalho já referenciado. Metzler (2011) trata das relações entre os poderes político e religioso na construção de representações identitárias de ensino superior de confessionalidade católica (IESCC) brasileiras. Realiza análise de documentos institucionais da IESCC e conclui que as influências do poder religioso ainda são significativas, mas há também polarizações entre os mantenedores, um voltado para a formação humanista e o outro que parece acreditar que esse propósito deve ser alterado para continuar se expandindo em um mercado competitivo. Vasselai (2001) fundamenta a confessionalidade no aprender a "ser", dentro do processo educativo, cujo preceito religioso é materializado na dimensão pedagógica. Como ambos os trabalhos apresentam este eixo temático "materialização da confessionalidade na educação" de maneira secundária, e por não ser o assunto central das obras, carecem de melhor desenvolvimento e conclusões sobre esse aspecto.

O quarto eixo temático, identidade institucional, está dividido em produções científicas de matriz confessional católica, metodista e adventista. De matriz confessional católica, se enquadram as obras de Passos Júnior (2011); Metzler (2011); Cruz (2008) e Araújo 
(2009). De matriz confessional metodista, as obras de Silva Júnior (2006); Vasselai (2001) e Cardoso (2016). Por último, Gonçalves (2009) de matriz adventista. ${ }^{5}$

Referente às obras de matriz confessional católica, Passos Júnior (2011) discute sobre a identidade institucional do ensino superior salesiano de São Paulo, questionando o alcance dos referenciais fundacionais na atualidade das IES salesianas, podendo vir a ser um simulacro de identidade institucional. Metzler (2011) reflete sobre a representação identitária de instituições católicas no período de 1995-2010 a partir da relação entre os poderes político e religioso. Entende que o poder religioso é mantido na medida em que se criam novos estabelecimentos. Cruz (2008), dissertação em Ciências Sociais, desenvolvida na Pontifícia Universidade Católica do Rio Grande do Sul (PUCRS), aborda a identidade sob o contraponto entre universidade ou empresa, constatando a mudança da cultura acadêmica com a inserção do conceito universidade-empresa. Araújo (2009) analisa a constituição da rede internacional das instituições salesianas de educação superior (IUS) como movimento criado com o objetivo de fortalecer sua identidade institucional. Constata que a estratégia de preservação da identidade institucional salesiana por meio da construção da rede IUS faz frente ao surgimento e expansão do modelo empresarial na educação superior.

Quanto às obras de matriz confessional metodista, Silva Junior (2006) contribui para o aclaramento do que pode vir a ser o modelo confessional, reconhecendo a contradição desse modelo educacional produzido pelo poder político instituído e seu impacto social. Vasselai (2001) busca verificar nas instituições confessionais, o que há de genuinidade da missão e seus reflexos na sociedade e o quanto há de preocupação teórica das instituições em imprimir em suas ações características, elementos que as diferenciem de outras instituições. Cardoso (2016), tese em educação desenvolvida na Universidade Metodista de São Paulo (UMESP), investiga o processo de constituição da identidade da Universidade Metodista de Piracicaba no movimento de construção de sua política acadêmica. Constata que o processo de construção identitária se deu a partir de suas posições contraideológicas e contrarreprodutivistas fortalecidas ao longo do tempo. Referente à matriz confessional adventista, Gonçalves (2009), dissertação em educação desenvolvida na UNIMEP, investiga os traços de uma universidade confessional presente na sociedade brasileira, em particular, o Centro Universitário Adventista de São Paulo (UNASP). Constata que a educação confessional adventista enfrenta os desafios impostos pela modernidade de secularização e mercantilização universitária.

No quinto eixo temático, confessionalidade e mercado, todas as obras analisadas apresentam elementos pertencentes a este eixo. De maneira mais direta e enfática, se enquadram as obras de Moraes (2013); Cruz (2008); Tavares (2009 e 2012) e Gonçalves (2009). Para tanto, Moraes (2013) avalia que, frente à competição do livre mercado educacional, a especificidade da orientação confessional da universidade investigada como objeto de pesquisa em nada interfere de maneira positiva nas relações que estabelece com a coletividade acadêmica do corpo técnico-administrativo e pedagógico. Cruz (2008) considera que as IES confessio-

\footnotetext{
5 A matriz adventista também é investigada por Carvalho (2012; 2017) sob a ótica das Ciências da Religião, apontando elementos da confessionalidade por meio do ensino religioso na educação básica e educação superior.
} 
nais estão em franco processo de mudança, deparando-se com o dilema de atuar como uma instituição sem fins lucrativos e ao mesmo tempo dar conta do mercado educacional. Tavares (2009 e 2012) investiga os caminhos que as IES confessionais vêm construindo e as práticas que lhes têm garantido o lugar que hoje ocupam no cenário universitário. Percebe que a dificuldade encontrada para a gestão das IES confessionais está enraizada, em certa medida, em um conflito de valores, entre uma concepção de universidade fundada em princípios éticos, humanistas e religiosos e a exigência de inserção em um mercado, onde prevalece o modelo de gestão gerencial. Gonçalves (2009) entende que se a situação de mercantilização da/na educação superior prevalecer, a unicidade dos ideais religiosos dos pioneiros, fundadores das unidades educacionais adventistas desaparecerá, resultando numa instituição de nível superior voltada apenas à transmissão de informações, sem o compromisso social.

Referente aos tipos de abordagem educacional, os trabalhos analisados se dividem em obras de perspectiva histórica medieval, moderna e colonial. Nos trabalhos de perspectiva medieval e moderna quanto ao escopo e referencial epistemológico, se enquadram as obras de Passos Júnior (2011) de matriz conceitual católica e Boaventura (2001) de matriz metodista; ambas as obras tendo a perspectiva histórica como elemento nuclear. A obra de Silva Júnior (2006), de matriz confessional metodista se enquadra na perspectiva moderna de modo secundário na condição de pano de fundo para o desenvolvimento de sua investigação. Quanto à abordagem histórica de perspectiva colonial, compreendendo a recuperação desse período para o entendimento do conceito e prática confessional nas atuais IES, se enquadram as obras de Santos (2003), de matriz confessional católica, e Vasselai (2001), e Tavares (2012), ambos de matriz metodista.

Passos Júnior (2011), tese em educação desenvolvida na Universidade Metodista de Piracicaba (UNIMEP), busca analisar se os propósitos inspiradores do período fundacional das unidades salesianas de educação do século XIX chegam ao século XXI, atingindo os objetivos educacionais propostos pelo fundador João Bosco. Por meio de abordagem historicista, método marxista, análise bibliográfica, sendo primária e secundária e, entrevista semiestruturada, constata um descompasso de ordem pastoral entre o que foi pensado no período fundacional das unidades salesianas do século XIX e o que é vivenciado atualmente na instituição universitária salesiana. Sua análise permeia os âmbitos pedagógico, técnico-administrativo e pastoral. Deixa pistas para trabalhos futuros que evidenciem a implicação de políticas educacionais nas IES confessionais. De maneira semelhante, Boaventura (2001), artigo em educação publicado pela revista de educação do COGEIME, analisa a dualidade da escola e da confissão. Por meio de análise bibliográfica e narração da experiência do autor no campo educativo e religioso, reconhece ser um problema o modo como igrejas se colocam no ensino, muitas vezes, arbitrariamente, para além da orientação confessional e pedagógica, acreditando estar legitimadas pelo uso do poder instituído na condição de mantenedora fiscal, econômica e administrativa.

A obra de Silva Júnior (2006) se enquadra na abordagem histórica de modo secundário com relação à educação superior confessional. Trata-se de um artigo em educação publicado pelo GT Política de Educação Superior/ANPEd. Destaca como centro temático 
a categoria "confessionalidade" na sua qualidade epistêmica e histórica presente nas instituições de educação superior brasileiras. Estabelece um paralelo analítico com os modelos de ensino francês e alemão, acrescentando hipóteses e proposições sobre essa categoria a partir de sua experiência profissional docente em instituições confessionais. Conclui que, de maneira paradoxal, a confessionalidade nega a história e a identidade da instituição universitária e de sua função social, historicamente, construída na medida em que restringe a concepção de educação superior à doutrina religiosa, como sendo uma extensão de outras frentes educacionais, que são nucleadas e normatizadas pelo poder religioso. Deixa pistas para trabalhos futuros que analisem a dimensão política e econômica das IES confessionais como maneira de inferir sobre sua identidade confessional.

As obras de Santos (2003), Vasselai (2001) e Tavares (2012) apresentam uma abordagem histórica, resgatando elementos da confessionalidade presentes no período colonial, concebidos como importantes no atual cenário da educação superior confessional. Santos (2003), dissertação em educação desenvolvida na Pontifícia Universidade Católica de Goiás (PUC-GO), buscou entender a constituição do departamento de economia (ECO), da Universidade Católica de Goiás, desde sua criação, em 1950, até os dias atuais. Utiliza entrevistas a quinze pessoas vinculadas ao departamento de economia, obtendo resultados factíveis ao constatar que, por conta da conjuntura econômica neoliberal, que estimula a competitividade entre as IES, cursos e instituições são montados, muitas vezes sem as mínimas condições de funcionamento e qualidade necessárias. Vasselai (2001), dissertação em educação desenvolvida na Universidade de Campinas (UNICAMP), buscou verificar as interferências concretas da confessionalidade nas instituições de ensino. Por meio de análise bibliográfica e de documentos institucionais da Universidade São Francisco (USF) _ (católica) e da Universidade Metodista de Piracicaba (UNIMEP) - (metodismo), conclui que as instituições confessionais de educação no Brasil representaram e representam importante papel no desenvolvimento da cultura e do conhecimento do povo. Tavares (2012), tese em educação desenvolvida na Universidade Federal de São Carlos (UFSCAR), investigou as consequências das reformas na educação superior realizadas na década de 1990 na identidade e gestão das universidades confessionais, bem como as transformações que vêm sofrendo nesse cenário. Utilizou pesquisa bibliográfica e análise de dados de quatro universidades do Estado de São Paulo: duas confessionais e duas de segmento particular de mercado. De modo semelhante a Vasselai (2001), ampliando, no entanto, sua perspectiva sobre a confessionalidade na educação, entende que as IES confessionais têm de enfrentar a superação do modelo de universidade inicialmente implantado no Brasil em meados do século XX para um novo modelo de universidade. Trata-se de algo em construção, ainda não consolidado. Nessa obra, considerou-se com relevância o referencial normativo da legislação educacional brasileira, deixando pistas para futuros trabalhos que investiguem as consequências das reformas educacionais pela vertente pedagógica e didático-científica.

Há também obras desenvolvidas em abordagem macro e micro-educacional. Macro educacional como bloco temático ligado aos sistemas de ensino e políticas de Estado (SOUZA, 2001); enquadram-se as obras de Cruz (2008); Tavares (2009; 2012) que tratam 
sobre as reformas da educação superior da década de 1990 e o modelo de governança no sistema de ensino confessional; e Muckenberger (2014), que analisa o processo de internacionalização do ensino superior a partir de casos múltiplos do sistema de ensino superior confessional internacional.

Referente ao tipo de abordagem micro-educacional foram analisadas doze obras que se enquadram na análise voltada às IES, funções da universidade, cursos, currículos e programas, alunos e professores e o que mais houve nessa esfera (SOUZA, 2001). As obras de Passos Júnior (2011); Silva Júnior (2011); Vasselai (2001) e Gonçalves (2009) refletem sobre o cenário confessional em IES localizadas. Alvim (1995) e Boaventura (2001) tratam das funções da universidade com o olhar mais voltado à Universidade Metodista de Piracicaba (UNIMEP). Cericato (2006); Metzeler (2011); Cardoso (2016) e Araújo (2009) analisam os currículos e programas de IES confessionais. Santos (2003) reflete sobre o curso e departamento de economia numa IES confessional, e Moraes (2013) trata sobre o profissional docente num contexto de IES confessional. A predominância de trabalhos representativos de abordagem micro-educacional em comparação ao macro-educacional revela, hipoteticamente, a ausência de referenciais normativos, bem como, do ponto de vista sociocultural, o fortalecimento de juízos que apregoem da confessionalidade dever restringir-se à igrejas, diminuindo, assim, as possibilidades de exploração e investigação do assunto numa perspectiva macroestrutural.

Conforme apresentação dos trabalhos descritos, estes eixos temáticos e tipos de abordagem educacional são os mais recorrentemente tratados na pesquisa sobre a confessionalidade na educação superior no Brasil. Embora sejam de naturezas diferentes, são coadunados pela categoria "confessionalidade", pelo tempo histórico das produções, circunscritos nos primeiros anos do século XXI, e pelo cenário sociocultural que tem em seu bojo parâmetros e critérios da doutrina neoliberal que, por sua vez, têm impelido as IES confessionais a revisarem suas concepções identitárias, políticas acadêmicas, relação com o mercado e maneira de inserção social.

\section{CONSIDERAÇões}

Este trabalho buscou apresentar o panorama da pesquisa sobre a confessionalidade na educação superior no Brasil, objetivo auspicioso num cenário educacional subserviente ao modelo político e econômico neoliberal assumido pelo Estado brasileiro nas últimas décadas do século XX e intensificado nesta segunda década do século XXI.

Tendo apresentado brevemente a evolução da educação superior no Brasil e sua consequente metamorfose de concepção, função e implicações socioculturais na comunidade, refletiu-se sobre a categoria "confessionalidade" a partir do lugar que ocupa nos documentos normativos, eclesiais e acadêmicos, bem como o modo que é assumida e problematizada no universo da educação superior no Brasil.

Trata-se de uma temática pouco explorada na agenda da pesquisa educacional brasileira. Se, por um lado, o referencial normativo civil é pouco abrangente a respeito da espe- 
cificidade da educação superior confessional, por outro, o referencial normativo eclesial, relativamente recente na história da educação superior confessional, apresenta consistência em sua estrutura documental, mas de tênue relação entre "fé e razão", com certa prevalência simbólica da fé sobre a razão. Quanto às obras analisadas, destaca-se o enfrentamento dos princípios confessionais com os parâmetros de mercado utilitarista, pragmatista e gerencial, impactando na concepção identitária e linhas de ação operativa de considerável número de IES confessionais. Conforme análise realizada, muitas dessas IES confessionais estão em processo de revisão identitária, outras em progresso rumo à adesão de modelo de gestão gerencial, ainda que de modo sutil pelas equipes de gestão, na medida em que apenas pretendem sobreviver no mercado educacional universitário.

Dos eixos temáticos e tipos de abordagem educacional mais recorrentemente tratados sobre a confessionalidade na educação superior no Brasil, destaca-se a "identidade", percebida, ora de maneira direta, ora menos direta em doze obras de micro-estrutura educa-

cional, revelando o esforço local de entender como se constituem como instituição de nível superior, que supere a esfera do poder religioso; também o eixo temático "confessionalidade e mercado" presente em todas as obras analisadas, confirma o cenário de imposições de critérios e parâmetros do modelo político e econômico neoliberal na educação superior. A vinculação dessas observações exibidas ao longo do texto com o referencial teórico normativo e literário confirmam certo prognóstico de desmonte da educação superior, sobretudo confessional, que não apenas se ressente da dificuldade de evoluir e se adequar identitariamente aos novos tempos, mas também por motivos de sustentabilidade financeira, se permite seguir alinhamentos neoliberais em suas práxis acadêmicas, metamorfoseando, fortemente, sua concepção confessional.

Evidenciando este breve panorama da pesquisa sobre a confessionalidade na educação superior no Brasil, percebe-se a viabilidade de trabalhos futuros que tratem sobre a relação e implicação das políticas educacionais voltadas ao ensino superior confessional, questionando à luz desse cenário de pesquisa já trilhado, o atual lugar, papel e função da confessionalidade na educação superior no Brasil e no mundo.

\section{REFERÊNCIAS}

ALVIM, Gustavo Jacques Dias. Autonomia universitária e confessionalidade. Prefácio de Almir de Souza Maia, 2. ${ }^{a}$ ed. Revista. Piracicaba: Editora UNIMEP, 1995.

ANTONIAZZI, A. Tendências atuais das universidades católicas no Brasil. Petrópolis: Vozes, v. 69, n. 9, out. 1975.

AQUINO, Luiz Carlos Andrade de. O agir comunitário na UNIVAP: Limites e possibilidades. Tese (Doutorado em Educação) - Programa de Pós-Graduação em Educação, Universidade Metodista de Piracicaba, Piracicaba - SP, 2017 - 185s. 
ARAÚJO, Jair Marques de. O processo de implantação da rede internacional das instituições salesianas de educação superior e a afirmação da identidade confessional salesiana. Dissertação (Mestrado em Educação) - Universidade Católica Dom Bosco, Campo Grande, 2009, 162 s.

BITTAR, Mariluce. Universidade Comunitária: uma identidade em construção. Tese (Doutorado em Educação) - Programa de Pós-Graduação em Educação, Universidade Federal de São Carlos, São Carlos-SP, 1999.

BOAVENTURA, Elias. Evolução histórica do conceito de confessionalidade no metodismo brasileiro. Revista de Educação do Cogeime. Ano 10, n. ${ }^{\circ} 18$ - jun/2001. Disponível em: <http://www.cogeime.org.br/revista/cap0118.pdf $>$. Acesso em: 20 jun. 2017.

BRASIL. Constituição da República Federativa do Brasil. Brasília: Senado Federal, Centro Gráfico, 1988.

BRASIL. Lei de Diretrizes e Bases. Lei nº 9.394/96, de 20 de dezembro de 1996.

BUARQUE, Cristovam. A Aventura da Universidade. São Paulo: Editora da UNESP; Rio de Janeiro: Paz e Terra, 1994.

CARDOSO, Luís de Souza. A identidade da Unimep no movimento de sua política acadêmica: uma teoria fundamentada nos dados. Tese (Doutorado em Educação) - Universidade Metodista de São Paulo, São Bernardo do Campo, 2016, 274 s.

CARVALHO, Francisco Gomes de. O Ensino Religioso no Ensino Superior da Educação Adventista: presença e impasses. Dissertação (Mestrado em Ciências da Religião) - Programa de Pós-Graduação em Ciências da Religião, Pontifícia Universidade Católica de São Paulo, PUC/SP, Brasil, 2012.

. ADVENTISMO E EDUCAÇÃO NO BRASIL: a formação do obreiro no seminário / Colégio Adventista brasileiro e a experiência religiosa de obreiros jubilados. Tese (Doutorado em Ciências da Religião) - Programa de Pós-Graduação em Ciências da Religião, Universidade Federal de Juiz de Fora, UFJF, Brasil, 2017.

CERICATO, Domingo. Fontes de financiamento nas universidades de caráter confessional do estado do Rio Grande do Sul. Dissertação (Mestrado em Administração) - UFSC, 2006, 89 s.

CHAUÍ, Marilena de Sousa. A Universidade Operacional. Revista da Adunicamp, Campinas, ano 1, n 1.6, p. 6-9, jun. 1999. Disponível em: <http://www2.unifap.br/borges/ files/2011/02/A-Universidade-Operacional-Marilena-Chau\%C3\%AD.pdf $>$. Acesso em: 20 jun. 2017. 
CHESNAIS, François. A mundialização do capital. São Paulo: Xamã, 1996.

CRUZ, Carmem Lucia Castro da. Universidades ou empresas? A identidade das universidades confessionais frente à competitividade global na sociedade contemporânea. Dissertação (Mestrado em Ciências Sociais) - Pontifícia Universidade Católica do Rio Grande do Sul, 2008, 206s.

CURY, C. R. J. Quadragésimo ano do parecer CEF N. ${ }^{\circ}$ 977/65. Revista Brasileira de Educação. Rio de Janeiro, n. 30, p. 7-20, set/dez. 2005. Disponível em $<$ http://www.scielo. br/scielo.php?script=sci_arttext\&pid $=\mathrm{S} 1413-24782005000300002 \& \ln g=$ en $\&$ nrm $=$ iso\&t1 ng $=\mathrm{pt}>$. Acesso em: 20 jun/. 2017.

DIAS SOBRINHO, José. Universidade fraturada: reflexões sobre conhecimento e responsabilidade social. Revista Avaliação, Campinas; Sorocaba, SP, v. 20, n. 3, p. 581-601, nov. 2015.

DREZE, Jacques; DEBELLE, Jean. Concepções de Universidade. Fortaleza: Edições Universidade do Ceará, 1983.

DURHAM, Eunice R. O ensino superior no Brasil: público e privado. Documento de Trabalho do núcleo de pesquisa sobre o Ensino Superior da Universidade de São Paulo, 2003. Disponível em: $<$ http://nupps.usp.br/downloads/docs/dt0303.pdf $>$. Acesso em: 9. mai. 18.

ESTUDOS DA CNBB 102. O seguimento de Jesus Cristo e a ação Evangelizadora no Âmbito Universitário. $1^{\text {a }}$. Ed. 2013.

EX CORDE ECCLESIAE. Constituição Apostólica sobre as Universidades católicas. São Paulo: Paulinas, 1990. Disponível em: $<\underline{\text { http://w2.vatican.va/content/john-paul-ii/pt/ }}$ apost constitutions/documents/hf_jp-ii_apc 15081990 ex-corde-ecclesiae.html $>$. Acesso em: 20 jun. 2017.

FERREIRA, Suely; OLIVEIRA, João Ferreira de. Reformas da educação no Brasil e na união europeia e os novos papéis das universidades públicas. Revista Nuances: estudos sobre Educação. Ano XVII, v. 17. n. 18, p. 50-67, jan./dez. 2010. Disponível em: $<\underline{\text { http:// }}$ revista.fct.unesp.br/index.php/Nuances/article/view/724/737>. Acesso em: 20 jun. 2017.

FRIEDMAN, M. Capitalismo e Liberdade. 2a . ed. São Paulo: Nova Cultural, 1985.

GOERGEN, P. A instituição universidade e sua responsabilidade social: anotações críticas. Quaestio, Revista de estudos da educação. Sorocaba, v. 4, no. 1, p. 9-25, mai. 2002. Dispo-

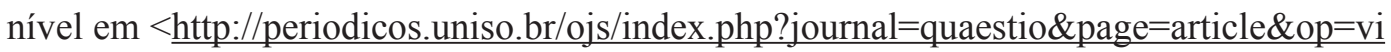
ew\&path\%5B\%5D=1393>. Acesso em: 20 jun. 2017. 
Adventista de São Paulo. Mestrado em Educação, Universidade Metodista de Piracicaba, INEP, 2009, 108s.

GUEDES, M. D; MURANAKA, M.A.S.; ARAGÃO, J. E. O. S. Políticas de avaliação da educação superior no Brasil de FHC a Lula: uma análise crítica dos seus pressupostos e fundamentos. Revista Ciências da Educação, Americana, ano XVIII, n. 34, p. 103-122, jan./jun. 2016. Disponível em: <http://revista.unisal.br/ojs/index.php/educacao/article/ view/491/361>. Acesso em: 20 jun/. 2017.

KERR, Clark. Os Usos da Universidade. Fortaleza: Edições UFC, Universidade Federal do Ceará, 1982.

MACEDO, Elizabeth. Cultura performativa e pesquisa em educação: desafios para a ação política. Cadernos de Pesquisa, São Paulo, v. 45, n. 158, p. 752-774, dez. 2015. Disponível em http://www.scielo.br/scielo.php?script=sci arttext\&pid=S0100-15742015000400752\&lng $=$ pt\&nrm=iso. Acesso em: 20 jun. 2017.

MANCEBO, Deise; VALE, Andréa Araújo do; MARTINS, Tânia Barbosa. Políticas de expansão da educação superior no Brasil (1995-2010). Revista brasileira de Educação, v. 20,

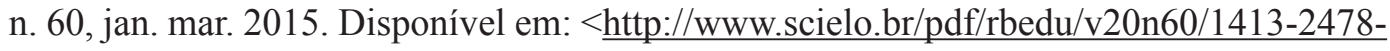
-rbedu-20-60-0031.pdf>. Acesso em: 20 jun. 2017.

MARTINS, Carlos Benedito. A Reforma Universitária de 1968 e a abertura para o ensino superior privado no Brasil. Educ. Soc., Campinas, v. 30, n. 106, p. 15-35, jan./abr. 2009.

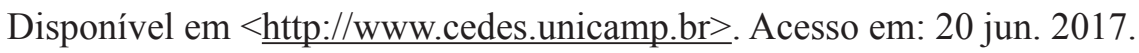

METZLER, Ana Maria Carvalho. Relações entre os poderes político e religioso na construção de representações identitárias de instituições de ensino superior de confessionalidade católica. Tese (Doutorado em Educação). São Leopoldo: Universidade do Vale do Rio dos Sinos, 2011,193s.

MORAES, Maria Laura Brenner de. Condições de trabalho docente no contexto confessional comunitário mercantilizado: um estudo de caso. Tese (Doutorado em Educação) Universidade Federal de Pelotas, 2013, 119s.

MUCKENBERGER, Everson. Processo de internacionalização do ensino superior: Estudo de casos múltiplos em um sistema de ensino superior confessional internacional. Tese (Doutorado em Administração) - Universidade de São Paulo, 2014, 627s.

PASSOS JÚNIOR, Dílson. O Ensino Superior no Centro Universitário Salesiano de São Paulo - UNISAL - Discutindo sua identidade salesiana. Tese - (Doutorado em Educação) - UNIMEP, 2011, 325s. 
PAULANI, Leda Maria. Brasil Delivery: A Política Econômica do Governo Lula. Revista de Economia Política, v. 23, nº 4 (92), out. - dez, 2003. Disponível em: $<$ http://www.rep. org.br/PDF/92-4.PDF $>$. Acesso em: 20 jun. 2017.

. Brasil Delivery: servidão financeira e estado de emergência econômica. São Paulo: Boitempo, 2008.

PROTA, Leonardo. Um novo modelo de Universidade. São Paulo: Convívio, 1987.

SALEM, T. Do Centro Dom Vital à Universidade Católica. In: SCHWARTZMAN, S. (Org.). Universidades e instituições católicas no Rio de Janeiro. Brasília, DF: CNPq, 1982.

SANTOS, MIGUEL ROSA DOS. A Expansão das Instituições Católicas, o Ensino Superior em Goiás e o Departamento de Economia da Universidade Católica de Goiás: história e memória. Dissertação - (Mestrado em Educação) - Pontifícia Universidade Católica de Goiás, Goiânia, 2003, 243s.

SCHMIDT, João Pedro. O Comunitário em Tempos de Público não Estatal. Avaliação, Campinas; Sorocaba, SP, v. 15, n. 1, p. 9-40, mar. 2010. Disponível em: $<\underline{\text { http://www.scie- }}$ lo.br/scielo.php?pid $=\mathrm{S} 1414-40772010000100002 \&$ script $=$ sci abstract\&tlng $=\mathrm{pt}>$. Acesso em: 20 jun. 2017.

SGUISSARDI, Valdemar. Reforma universitária no Brasil - 1995-2006: Precária trajetória e incerto futuro. Revista Educação \& Sociedade, Campinas, v. 27, n. 96 - Especial, p. 1.021-1.056, out. 2006. Disponível em: $<$ http://www.scielo.br/pdf/es/v27n96/a18v2796. pdf $>$. Acesso em: Acesso em: 20 jun. 2017.

. Universidade brasileira no Século XXI. São Paulo: Cortez, 2009.

. Regulação estatal e desafios da expansão mercantil da educação superior. Educ. Soc. v. 34 n. 124, Campinas Jul/set. 2013. Disponível em: <http://www.scielo.br/scielo. php?script $=$ sci_arttext\&pid $=$ S0101-73302013000300015>. Acesso em: 20 jun. 2017.

SILVA JÚNIOR, João dos Reis. Universidade Metodista de Piracicaba (UNIMEP): Haverá um modelo confessional de universidade brasileira. In: MOROSINI, Marilia. (Org.) A Universidade no Brasil: concepções e modelos. Brasília: Instituto Nacional de Estudos e Pesquisas Educacionais Anísio Teixeira, 2006.

SOUZA, Paulo Nathanael Pereira de. LDB e educação superior: (estrutura e funcionamento). $2^{a}$ Ed. ver. e ampl. São Paulo: Pioneira Thomson Learning, 2001.

TAVARES, Sergio Marcus Nogueira. Governança em universidades confessionais no Brasil: modelo em construção. Revista Educação \& Linguagem. v. 12 n. 19 p. 219-238, jan./ jun. 2009. 
- As universidades confessionais brasileiras e as reformas da educação superior da década de 1990. Tese (Doutorado em Educação). São Carlos: UFSCar, 2012, 260s.

TEIXEIRA, Anísio. A Universidade de Ontem e de Hoje. Rio de Janeiro: Ed. UERJ, 1998.

VASSELAI, Conrado. As Universidades confessionais no ensino superior brasileiro: identidades, contradições e desafios. Dissertação (Mestrado em Educação) - UNICAMP, 2001.

Doutorando do Programa de Pós-Graduação em Educação - Universidade Metodista de Piracicaba - UNIMEP. Mestre pelo Centro Universitário Salesiano de São Paulo - UNISAL, unidade de Americana, SP. Professor do Centro Universitário Salesiano de São Paulo - UNISAL, unidade São José/Campinas, SP. E-mail: ir.tarcharo@hotmail.com

Submetido em: 3-2-2018

Aceito em: $23-8-2018$ 